\title{
Jornalismo
}

\section{A retórica nos estudos de jornalismo e da comunicação: o potencial político do rhetorical criticism}

The rhetoric studies in journalism and communication: the political potential of the rhetorical criticism

\section{Geder Parzianello}

Doutor em Comunicação pela Pontifícia Universidade Católica do Rio Grande do Sul (PUCRS). Professor da Universidade Federal do Pampa (UNIPAMPA). São Borja, RS, Brasil.

<geder@unipampa.edu.br>

\section{RESUMO}

Os estudos de comunicação são devedores da tradição retórica. A heterogeneidade de paradigmas que os constituem, a diversidade de métodos e a interdisciplinaridade bem pouco ortodoxa desse campo não foram ainda suficientes para ver reconhecidas nos estudos retóricos as dimensões investigativas de novas perguntas que remontam a velhas questões nos communication studies. Este artigo percorre o argumento em defesa desse resgate que é devido à retórica pela comunicação social e fornece, por meio de metodologia de pesquisa qualitativa e bibliográfica, as conclusões na direção de uma pesquisa em comunicação que se veja desafiada a novos domínios teóricos, tanto no Brasil quanto para além de nossas fronteiras.

Palavras-chave: Retórica. Comunicação Social. Jornalismo.

\begin{abstract}
Communication studies are debtors of the rhetorical tradition. The heterogeneity of paradigms constitutes the diversity of methods of an unorthodox and interdisciplinary field. Rhetorical studies had no recognition for investigative dimensions of the new questions that go back to old issues in communication research. This paper examines the argument for such redemption that is due to the social communication and rhetoric; it provides, through qualitative methodology and bibliographical research, findings toward a communication research that demands new theoretical areas in Brazil and beyond our borders.
\end{abstract}

KeYwords: Rhetorics. Social Communication. Journalism. 
- stamos vivendo uma época de resgate dos estudos de retórica e vendo com$\amalg$ preendida sua verdadeira aplicação diante das carências comunicativas de nosso tempo. Sua atualidade e revisão fornecem evidências de que as condições socioculturais e políticas afinam as necessidades comunicacionais de cada época e nos servem também de auxílio para uma comunicação mais eficaz e uma compreensão menos limitada do potencial persuasivo da comunicação humana, a partir do entendimento assentado na linguística dos anos 70 e na filosofia da linguagem que a precedeu, no sentido de que nenhum ato de linguagem é inocente e de que toda comunicação é necessariamente persuasiva.

Os estudos retóricos vêm deixando, por isso mesmo, de figurar circunscritos apenas frente a uma "literaturização" secular aliada à fundamentação estética. O pragmatismo que a inspira no século XIX, com efeito, não é o mesmo desse século XXI, em que a retórica se encontra ainda mais interdisciplinar e ainda mais aplicada do que nunca. Mas há, ainda, um longo percurso a percorrer e que requer dos pesquisadores, sobretudo da área da comunicação, um olhar menos preconceituoso e menos estreito sobre um conhecimento que remonta a mais de quatro séculos antes do começo da Era Cristã e que vem sendo atualizado de forma sistemática desde metade do século passado, tendo este conhecimento sido mais aproveitado nos estudos jurídicos, no campo do Direito e em respeito a estratégias argumentativas na compreensão de processos comunicacionais e práticas profissionais como a do jornalista.

\section{A nova retórica}

Os esforços pela revisão sistemática da retórica e pela atualização de suas abordagens e aplicações pode se ver marcado historicamente desde os estudos de Perelman e Tyteca, publicados na década de 50, notadamente desde o Tratado da argumentação, 
em 1957, com o qual esses pesquisadores insistiam na necessidade de uma revisão histórica da valoração dos estudos retóricos, preteridos desde a Antiguidade Clássica em favor da dialética e que rendeu para a retórica um lugar injusto, como se estivesse em oposição e não em complementariedade à dialética. O seu sentido e essência foram deturpados, reduzida que esteve por séculos a um entendimento enquanto arte ou técnica de falar de forma elegante ou enfeitada ou, pior, enquanto instrumento de enganar e confundir. Colocada dessa forma, de fato, ela reunia elementos suficientes para ser desprestigiada entre pesquisadores das novas gerações.

Importa reconhecer, todavia, que a retórica surgida na Sicília, como resultado da expulsão de Trasíbulo, deposto do poder durante as revoltas de Agrigento e de Siracusa em 465 a.C., foi uma marca da liberdade democrática da comunicação social daquele tempo, já que por seu meio permitiam-se ver conhecidas as tensões e controvérsias legais surgidas no regime da tirania. A finalidade na funcionalidade democrática fez da retórica uma orientação da comunicação humana em situações de debate e argumentação que, já naquela época, ultrapassavam a aplicabilidade persuasiva negativa que a história lhe reservaria. Se por um lado, a retórica conduzia almas e teve uma função sofística, mais tarde, quando levada a Atenas, por outro, não foi menos importante a percepção de que no domínio da persuasão os cidadãos estariam mais preparados para também se defender na revisão dos direitos pela discussão pública no regime democrático que constituía a Sicília. Os jurados populares, constituídos para tal propósito, melhor dominavam a linguagem do que pareciam dominados por ela, o que é, aliás, desejável que possam estar os sujeitos implicados em quaisquer situações comunicativas.

Cervantes (2009, p. 233) afirma que "é correto destacar que em Roma a liberdade da palavra exercida pelos cidadãos nos debates públicos [...] com seus seiscentos membros [...] tornou possível a existência de um discurso político prático". Na visão 
desta pesquisadora, os romanos souberam se valer do conhecimento dos retóricos gregos e reconhecer em nomes como o de Cícero, brilhante orador e defensor da retórica, esta arte como inserida na filosofia. Desde nossa defesa argumentativa, a retórica também se encontra inserida na comunicação e precisa ser, assim, cada vez mais compreendida e revalorizada.

Muniz Sodré confirma essa tendência ao afirmar que "no vaivém das aceitações e recusas, a retórica volta à cena pública com muita força e com outro nome: comunicação". Como na origem, diz ele, trata-se de "uso político do discurso" (Sodré, 2009, p. 354). Uma sociedade global midiática e seu novo bios vai ordenar de forma distinta a argumentação e se impor segundo o teórico, como uma nova natureza, uma nova presença do sujeito no mundo. Em outras palavras, trata-se de impor uma nova realidade, como descreve Igor Sacramento:

Há um processo de virtualização tal que a simulação midiática é tomada como mais perfeita que a realidade, porque se coloca como autossuficiente por ser autoreferente. Faz como se não dependesse do real, já que cria um real. Instaurou-se, assim, um novo regime de verdade - e de produção de verossimilhança."

(Sacramento, 2009, p. 207)

Todo um conjunto de análises sobre formas narrativas textuais midiatizadas e que vemos de forma recorrente no cenário da pesquisa em comunicação são, em verdade, perspectivas retóricas de investigação dos media, ainda que seus autores pesquisadores não reconheçam assumidamente essa tradição e também se encontrem 
entre eles aqueles que insistem em creditar certa originalidade a preocupações quase milenares.

\section{Rhetorical criticism}

A investigação sistemática dos atos e artefatos simbólicos criam oportunidades de uma comunicação mais efetiva. Nos Estados Unidos, boa parte dos esforços contemporâneos nessa direção vem sendo conhecidos como rhetorical criticism e levados à compreensão de que a evolução dos processos comunicacionais pode nos fazer compreender a necessidade de criarmos nossas próprias respostas simbólicas, capazes de gerar os sentidos e as interpretações que desejamos.

Sonja Foss (2009) define rhetorical criticism como um processo por meio do qual nós escolhemos comunicar de uma forma particular, baseada no que descobrimos a partir de como os símbolos nos afetam. A autora apresenta nove métodos de crítica retórica e encoraja pesquisadores a formarem seus próprios modelos críticos. Este é um ponto que certamente nos instiga: investigar processos comunicacionais na perspectiva de um pensamento teórico, de fato, minimamente original. Mesmo porque, em que pese uma evidente concentração no Brasil de estudos teóricos de origem norte-americana, é fato que muito pouco se tem encontrado por aqui no sentido de abordagens interdisciplinares capazes de favorecer a convergência entre investigações retóricas e teóricas em comunicação social, desde matrizes conhecidas nos Estados Unidos ou mesmo de culturas mais distantes de nossas academias. Ambas as áreas, a retórica e a comunicação são, por natureza, conhecimentos interdisciplinares, que podem e devem cooperar entre si, estabelecendo novos paradigmas.

No campo do jornalismo, por exemplo, as investigações retóricas se somam aos esforços já bastante disseminados de estudos do discurso e cujos métodos qualitativos permitem enquadramentos investigativos, não apenas acerca de suas estruturas, 
mas de interpretações e sentidos em torno dos sujeitos que ali se constituem, seus empenhos persuasivos e suas determinações estratégicas, bem como os efeitos produzidos. Cada uma dessas perspectivas enseja uma ou mais teorias da comunicação, mas também lida com conhecimentos de tradição, seja grega ou romana, nos estudos clássicos de retórica e em muitas das atualizações a que historicamente a retórica encampou. Suas interferências são significativas o suficiente para que possamos falar em retóricas do discurso e/ou em uma série de outras determinações conceituais, haja vista que, não sem enorme frequência, exista certa recorrência nas pesquisas sobre discurso, sobre comunicação ou sobre linguagem no jornalismo e que parecem desconhecer, ignorar ou mesmo desejar não favorecer qualquer convergência entre tradições clássicas e o conhecimento que as sucedeu e falam de perspectivas diacrônicas, como se nelas não se pudessem reconhecer traços sincrônicos fundadores, afirmados por filósofos gregos, reafirmados de outras tantas formas, por tantas outras tradições, sem atribuir-lhes os devidos créditos.

Um simples exemplo que aqui cabe de forma ilustrativa, sem intenção de esgotar qualquer potencial crítico do argumento, é o estudo sobre o ethos nas perspectivas da moral e da ética, da filosofia política, do jornalismo e da comunicação, os quais, muitas vezes, parecem sugerir que se trate de um vocábulo contemporâneo, pensado na conjuntura da cultura de nosso tempo e em paradigmas necessariamente descolados da tradição clássica.

Ora, os gregos de Siracusa já se preocupavam com questões éticas no que dizemos e com tipologias e estratégias, que precisamos parar de pensar como se descoladas da tradição retórica. Com frequência, citamos autores próximos de nós ou leitores de nossa tradição e formação. Mas, se este recurso tem alguma aplicabilidade funcional na dinâmica da produção científica, sobretudo diante da lógica produtivista em que grande parte de nós se encontra amarrada, não deve isso indiciar a limitação de nossa capacidade de ver problemas de pesquisa e abordagens, sejam elas quais forem, em 
uma razoável compreensão histórica e evolutiva conceitual, acabando por se constituir em torno dela uma consistente epistemologia. Tal empenho, a nosso ver, representa o potencial político para a área da comunicação.

O desconforto gerado por estudos sem suficiente compreensão históricoconceitual, excessivamente pragmáticos e capazes de pensar seus objetos-problema não apenas atuais, mas, sobretudo, presos à compreensão na atualidade, configura a muitas conclusões e perspectivas a fragilidade que, por extensão, enfraquece a área e tensiona os limites a que se poderia chegar, caso fôssemos capazes de oferecer a convergência do contemporâneo com os limites da tradição.

As ocorrências temáticas da retórica nos estudos de comunicação são, no entanto, e em razão disso, bastante difusas e raramente centrais nos trabalhos, artigos, teses e dissertações que foram produzidos no Brasil. Um levantamento a respeito é feito em nossa pesquisa publicada em 2013, com apoio do Instituto de Pesquisa Econômica Aplicada (IPEA), em que se apontam os estudos declaradamente retóricos em comunicação no Brasil. Na pesquisa realizada, foi possível evidenciar que a retórica ocupa, em geral, o espaço de uma referência ou outra, marginalmente citada, quando a investigação trata de aspectos relativos à forma de produtos midiáticos. A retórica está associada, em regra, a estudos da imagem, da persuasão na comunicação humana e sobre o uso de argumentos, quando aparece com alguma visibilidade no contexto da pesquisa em comunicação social. Sua contribuição, todavia, pode ir muito além e se tornar mais central, tanto enquanto referência teórica como metodológica.

Conforme Sodré (apud Melo, 2008, p. 71), “o comportamento interdisciplinar dos estudos da comunicação resulta da incômoda condição de estar comprimida entre as grandes disciplinas do pensamento social". Parece claro a eles que o objeto dos estudos de comunicação seja justamente a vinculação entre o "eu" e "o outro", seja do ponto de vista individual, seja do ponto de vista coletivo. Nada poderia ser mais propriamente vinculado à retórica que este objeto. Daí que podemos afirmar que toda 
investigação em comunicação é uma investigação retórica, ainda que formalmente suas referências não identifiquem.

O que percebemos é que o conhecimento sobre retórica, na pesquisa em comunicação das últimas quatro décadas, não aparece apropriado por pesquisadores de uma forma disciplinar e metódica, achando-se disperso, marcadamente difuso e, por vezes, apenas implícito na descrição dos estudos a que se teve acesso.

No conjunto das pesquisas em comunicação nos parece bastante clara a ausência de um saber mais efetivo sobre as práticas e concepções teóricas em torno da linguagem e das inter-relações humanas em situações comunicativas capazes de tributar à Antiguidade Clássica o reconhecimento que lhe cabe, haja vista os postulados que constituem os fundamentos da retórica. Houve uma espécie de desgaste do conhecimento dessa tradição em campos externos ao da filosofia, por se ver confundida com falsa erudição e mera estratégia de narrativa da reflexão teórica, que visava à aceitação entre os pares na academia. Com efeito, tal conhecimento não é trabalhado nos cursos de Jornalismo, Relações Públicas e ou de Publicidade e Propaganda, na graduação, e, mesmo na pós-graduação. Em geral, sequer constituem parte significativa de suas bibliografias complementares.

Quando as pesquisas em comunicação social, na grande área das Ciências Sociais Aplicadas, repercutem o pensamento de autores como Michel Foucault ou Jürgen Habermas, por exemplo, estas fazem atualizar muito mais do que foi pensado sobre linguagem entre os gregos, desde Aristóteles, ao que é conhecida como retórica clássica. É pena que quase nunca o emprego desses e tantos outros pensadores evidenciem reflexões da gênese dessas ideias e acabem por insistir em interpretações de autores contemporâneos, sob a impressão de uma genuinidade absoluta, sem reconhecer os vínculos fundadores das teses que enunciam. Muitas pesquisas parecem quase sempre datadas de um começo de percurso teórico relativamente recente. 
O fato é que há muito mais de Aristóteles e dos retóricos sicilianos de Siracusa nos escritos sobre comunicação contemporâneos do que se possa supor ou imaginar. Impossível seria, pois, identificar o conjunto destes elementos textuais e dizer o quanto da reflexão contemporânea em comunicação social possui raízes de preocupações legitimamente retóricas, no sentido clássico, assim como seria, evidentemente, impossível, da mesma forma, garantir, em tudo que se produz, o devido tributo à gênese dos conceitos. Mas, aqui falamos de um quase absoluto apagamento de referenciais teóricos, como se a considerar que as perguntas geradas em nosso tempo, bem como as respostas que se arrisca dar a elas, num esforço de compreensão, tenham sua existência apenas sincrônica, recortadas no tempo.

No âmbito das ciências da linguagem, os recortes em torno das questões da comunicação humana confundem, por vezes, correntes e autores, circunscrevendo, na lógica endógena de neologismos, a aparência de uma percepção nova sobre a realidade. É preciso reorganizar, por assim dizer, nos estudos de comunicação, e, por extensão, de jornalismo, os limites de contribuições vindas ora de uma retórica clássica, ora de estudos sobre retórica em perspectivas contemporâneas, e reconhecer suas proximidades e convergências com estudos em linguística, teorias do texto e do discurso, abordagens semióticas e outras vertentes.

$\mathrm{Na}$ ânsia de reclamar a centralidade de fundamentos teóricos e perspectivas de investigação, a comunicação continua em busca de uma epistemologia que lhe seja própria, mas permanece a negar a origem de suas preocupações em boa parte das reflexões da antiguidade grega.

É seguindo premissas como estas que até aqui procuramos descrever que queremos indicar alguns dos estudos de maior repercussão contemporânea no campo da retórica, sobretudo nos Estados Unidos. A justificativa é bastante simples: os estudos retóricos podem, a nosso ver, estar oferecendo respostas bem mais contundentes aos desafios do jornalismo e da comunicação de nosso tempo, em que pese que 
seus argumentos sejam ainda pouco difundidos no Brasil. Mesmo as pesquisas em retórica e mídia, que se fazem sentir por grupos de pesquisa em retórica em nosso país, não encontram acolhimento e repercussão entre pesquisadores da comunicação. Continuamos a depender de matrizes que ainda nos amarram a perspectivas sociológicas, filosóficas, psicológicas ou mesmo antropológicas. É preciso abrir essa interdisciplinaridade para outras ciências, não apenas para a retórica, mas para a ciência política e para as ciências novas que estão surgindo, ampliando, assim, perspectivas de compreensão de objetos e métodos. Assumo que o ponto de vista é polêmico, sobretudo porque isso pode fragilizar a ciência, na visão daqueles que defendem que o objeto define um domínio do conhecimento ou suas matrizes de pensamento, mas nos parece este, um desafio promissor.

Em The politics of new media (2012), Barbara Warnick e David Heineman unem diferentes conceitos retóricos a compreensões, ora oferecidas por Jürgen Habermas, em 1962, em Mudança estrutural da esfera pública, originalmente publicado em alemão, ora a estudos sobre funções e crítica discursiva dos novos meios, interatividade, narrativas, circulação, intertextualidade, identidade e mídia social, ativismo digital e uma série de outros enfoques.

Manuel Castells e suas abordagens sobre comportamento político reforçam a centralidade do campo do discurso retórico para pensar a comunicação e atualizam a retórica diante dos desafios da vida digital.

Warnick e Heineman (2012, p. 104) reafirmam a relevância do rhetorical criticism no estudo das mídias sociais e escrevem: "Enquanto teorias de identificação consubstancial e retórica constitutiva podem nos ajudar a compreender algo sobre as funções retóricas da mídia social. Estas duas abordagens não exaurem o potencial do rhetorical criticism na direção dos meios sociais". As coberturas políticas das guerras são provocativamente pensadas por um jornalismo que precisa se perguntar constantemente a quem são dirigidas as notícias que veicula e parece, forçosamente, 
nos levar a refletir quem celebra os conflitos ao promovê-las. Ultrapassa as abordagens do agenda-setting porque não coloca os atos discursivos como circunscritos apenas num tempo e lugar.

Ao propor reinventarmos os caminhos por meio dos quais lemos, escrevemos e respondemos aos outros, o professor John Muckelbauer (1969) publica em primeira edição The future of invention, em que convergem a retórica, o pós-modernismo e o problema da mudança na perspectiva da repetição e da reprodução midiáticas, tendo por modelo teórico conceitos de Derrida sobre a Difference e a filosofia de Gilles Deleuze. Tensões paradoxais presentes nos processos comunicacionais reúnem-se ali à luz de investigações filosóficas claramente amparadas por contribuições milenares dos estudos retóricos. Muckelbauer disseca os conceitos de inovação e de invenção desde Aristóteles e revela dobras teóricas que certas tradições paradigmáticas simplesmente ignoraram. Impossível não vislumbrar, com a ajuda do autor, o potencial sofístico de algumas das práticas comunicacionais de nosso tempo e perceber claramente que a retórica está mais presente do que nunca em nosso(s) meio(s) e não apenas por uma forma pejorativa de dominação persuasiva, como se articulada necessariamente para controlar corações e mentes.

A Retórica pode ter inspirado mesmo os ideais de toda uma geração de pensadores da sociologia inglesa e que tão largo amparo ela encontrou entre estudiosos da comunicação social, notadamente por conta dos estudos de recepção com a Escola de Birmingham, nos anos 60. Mas suas referências desaparecem nos autorizados tratados e antologias. Doxa e episteme, senso comum e contraditório, tudo sendo realocado teoricamente, desde matrizes do pensamento grego, e, compreendido que a evolução de suas abordagens é devedora da tradição que as identifica enquanto preocupações já existentes naquela arte, que foi uma das componentes do primeiro conhecimento formulado pelo homem, ao lado da gramática e da lógica. 
Incrível que, passadas mais de cinco décadas das principais publicações de Kenneth Burke, seus estudos ainda não sejam conhecidos nas escolas de comunicação nem tenham fomentado novas abordagens em pesquisa aplicada junto a Programas de Pós-graduação em Comunicação no Brasil. Filósofo de tradição retórica, ocupado com a linguagem e a conduta humana, ele soube expandir o campo da persuasão em A grammar of motives (1945), revista depois em A rhetoric of motives (1969). O campo investigativo interdisciplinar da filosofia da comunicação pode acolher perfeitamente boa parte desses estudos.

Há uma miríade de autores e trabalhos relevantes a serem citados. Seria impossível esgotar as indicações para a inclinação que pensamos necessária para que a pesquisa em comunicação e, por consequência, os estudos em Jornalismo, ampliassem seus campos teóricos com abordagens de domínio dos estudos da retórica. Nesse trabalho, centramos a indicação de alguns trabalhos em língua inglesa, seja pela facilidade com que atualmente o conhecimento consegue circular mais rapidamente nesse idioma, em diferentes ambientes acadêmicos, seja pelo fato de que é nos Estados Unidos que se fundam grandes tradições contemporâneas de retóricos, pesquisadores do mais amplo alcance da retórica e, não obstante essa constatação, suas contribuições parecem circunscritas a poucos contextos acadêmicos e ainda distantes demais dos pesquisadores da comunicação em toda a América Latina.

O que dizer de retóricos alemães e russos, eslovenos e tchecos e de outras tantas diferentes origens, cujos estudos possuem larga projeção no continente europeu e nos Estados Unidos, mas, infelizmente, são completamente ignorados no Brasil. O que tem a comunicação social a dizer sobre o futuro da comunicação escrita e em que sentido o conhecimento basilar da história em tradição grega, nesses autores, pode, hoje, ainda, reunir estratégias para o ensino da composição em escolas primárias e secundárias e nas escolas de jornalismo é a pergunta que se deve colocar. Invenção, revisão reflexão e análise, argumentação, estilo e gramáticas de uso, publicação e 
circulação, contexto e linguagem, são objetos não apenas de pedagogias ou pesquisas em educação e linguística, mas, que também podem, de forma interdisciplinar, ajudar a construir um desenho mais claro e justo historicamente sobre a comunicação e suas práticas, mesmo porque o contexto do ensino de práticas de linguagem que abarcam essas ênfases também se faz sentir, ora na formação de jornalistas, ora na compreensão de como os meios se relacionam com seus consumidores e de como as mensagens circulam e os sistemas as absorvem e fomentam tanto velhos modelos como novas mídias.

Educomunicação e retórica, jornalismo e estudos de seus auditórios, as estratégias textuais e seus efeitos, a força política dos media, as retóricas visuais nas mídias convencionais ou mesmo digitais, a retórica pensada na perspectiva do ethos jornalístico, enfim, investigações que, se alijadas das contribuições do campo dos estudos retóricos, apenas margeiam qualquer compreensão, de forma muito menos profunda do que poderiam fazê-lo.

Como postulado em Landowski (2002) o sentido não é jamais o simples produto de um pensamento diretamente confrontado com a realidade, mas resulta de uma negociação entre sujeitos. Ocorre que, se os sujeitos se limitam a outros de uma mesma cultura acadêmica, de um mesmo limite de campo ou tradição teórica, ou pior, a um mesmo recorte no tempo, jamais conseguiremos uma episteme para a comunicação, pelo que insistimos no argumento de que a natureza interdisciplinar da comunicação e a sua filiação retórica e a gênese clássica precisam ser sempre resgatadas, sendo atribuídas, declaradamente, para a retórica, a relevância e centralidade que a história lhe negou.

Quem sabe ainda muito em breve já possamos passar a formular, de forma mais sistemática e consistente, diversos constructos teóricos que repercutam internacionalmente e esbocem um rhetorical criticism in journalism made in Brazil. 


\section{REFERÊNCIAS}

BURKE, Kenneth. A Rhetoric of Motives. Califórnia: University of California Press, 1969.

. A Grammar of Motives. Nova Iorque: Prentice-Hall, 1945.

CERVANTES, Maria del Mar Gómez. Retórica: uma disciplina em consonância com as necessidades comunicativas de cada época. In: LOPES, Fernanda; SACRAMENTO, Igor (Org.). Retórica e mídia. Estudos ibero-brasileiros. Florianópolis: Insular, 2009.

FOSS, Sonja. Rhetorical criticism. Exploration and practice. Illinois: Waveland Press, 2009.

LANDOWSKI, Eric. Presenças do outro. São Paulo: Perspectiva, 2002.

MELO, José Marques de. O Campo da Comunicação no Brasil. Petrópolis: Vozes, 2008

PARZIANELLO, Geder. A retórica nos estudos em comunicação no Brasil: uma tentativa de mapeamento histórico. In: Panorama da comunicação e das telecomunicações no Brasil 2012/2013. Brasília: IPEA, 2013. Vol. 4.

PERELMAN, Chaïm. TYTECA, Lucie Olbrechts. Tratado da argumentação. A nova retórica. São Paulo: Martins Fontes, 1999.

SACRAMENTO, Igor. A retórica na sociedade midiatizada: a força-índice do verossímil. In: LOPES, Fernanda; SACRAMENTO, Igor (Org.). Retórica e mídia. Estudos ibero-brasileiros. Florianópolis: Insular, 2009.

. (Org.). Retórica e mídia. Estudos Ibero-brasileiros. Florianópolis: Insular, 2009.

MUCKELBAUER, John. The future of invention. New York: State University Press, 2008.

SODRÉ, Muniz. Antropológica do espelho: uma teoria da comunicação linear e em rede. Petrópolis: Editora Vozes, 2002.

In: LOPES, Fernanda; SACRAMENTO, Igor (Org.). Retórica e mídia. Estudos ibero-brasileiros. Florianópolis: Insular, 2009.

WARNICK, Barbara; HEINEMAN, David. Rhetoric on line. The politics of new media. New York: Peter Lang, 2012.

Recebido em: 30 maio 2014

Aceito em: 15 jun. 2014

\section{Endereço do autor:}

Geder Parzianello <geder@unipampa.edu.br>

Campus São Borja, Universidade Federal do Pampa

Rua Vereador Alberto Benevenuto, 3200 - Bairro do Passo

97670-000 São Borja, RS, Brasil 